\title{
Health-Related Quality of Life in Older Coastal Residents After Multiple Disasters
}

Katie E. Cherry, PhD; Laura Sampson, BA; Sandro Galea, MD, DrPH; Loren D. Marks, PhD; Kayla H. Baudoin, LMSW; Pamela F. Nezat, MHS-RC; Katie E. Stanko, MA

\section{ABSTRACT}

Objective: Exposure to multiple disasters, both natural and technological, is associated with extreme stress and long-term consequences for older adults that are not well understood. In this article, we address age differences in health-related quality of life in older disaster survivors exposed to the 2005 Hurricanes Katrina and Rita and the 2010 BP Deepwater Horizon oil spill and the role played by social engagement in influencing these differences.

Methods: Participants were noncoastal residents, current coastal residents, and current coastal fishers who were economically affected by the BP oil spill. Social engagement was estimated on the basis of disruptions in charitable work and social support after the 2005 hurricanes relative to a typical year before the storms. Criterion measures were participants' responses to the SF-36 Health Survey which includes composite indexes of physical (PCS) and mental (MCS) health.

Results: The results of logistic regressions indicated that age was inversely associated with SF-36 PCS scores. A reduction in perceived social support after Hurricane Katrina was also inversely associated with SF-36 MCS scores.

Conclusions: These results illuminate risk factors that impact well-being among older adults after multiple disasters. Implications of these data for psychological adjustment after multiple disasters are considered. (Disaster Med Public Health Preparedness. 2017;11:90-96)

Key Words: natural and technological disasters, Hurricane Katrina, Hurricane Rita, BP oil spill, post-disaster health and well-being

$\mathrm{M}$ any studies in the disaster science literature have addressed disasters and mental health. ${ }^{1,2}$ Relatively few studies have examined health outcomes after multiple back-to-back disasters. ${ }^{3-6}$ Residents of the US Gulf Coast have had a decade of catastrophic disasters in rapid succession with the 2005 Hurricanes Katrina and Rita and the 2010 BP Deepwater Horizon oil spill. Considered the worst human-made environmental disaster in US history, the BP oil spill has been a significant stressor for coastal residents struggling with hurricane recovery. ${ }^{7,8}$ Moreover, the oil spill has threatened the economy, commercial fishing industry, and cultural heritage of those whose livelihood depends on natural renewable resources. ${ }^{9-11}$ Understanding the long-term health consequences of consecutive catastrophic events is a pressing challenge from both psychological and public health perspectives. For instance, elevations in the prevalence of symptoms of depression and posttraumatic stress among residents of disaster-affected communities highlight the need for coordinated responses among mental health professionals, local officials, and urban planners to promote resilience and prepare for future disasters. ${ }^{4,6}$
There is ample evidence of health vulnerabilities among commercial fishers with recent trauma related to the BP oil spill. ${ }^{4,7,10,12}$ Cherry and her colleagues have shown that Katrina-related stressors and prior lifetime traumatic events predicted different styles of coping with oil spill stress for commercial fishers, although only avoidant coping was associated with increased risk of depression and post-traumatic stress. ${ }^{13}$ Cherry et al's first findings suggest that multiple disasters are devastating for coastal residents, particularly residents with economic ties to the commercial fishing industry. ${ }^{4,13}$ However, these findings are limited because they did not examine age-related differences in post-disaster health or health-related quality of life.

Prior research has shown that health and well-being are sensitive to demographic variables, including age, gender, education, and income. ${ }^{14,15}$ There is a small but growing literature on the impact of disasters on older $^{16-21}$ and oldest-old adults. ${ }^{22,23}$ From an epidemiological perspective, older adults are less likely than younger adults to survive disaster. ${ }^{24}$ However, older adults who live through disaster may fare better than 
their middle-aged and younger counterparts on mental health indicators, possibly due to prior experience or more effective coping strategies born of experience. ${ }^{15,21}$ Other evidence has shown that older survivors including nonagenarians and their younger counterparts were comparable across pre- and post-disaster measures of psychosocial and cognitive health, ${ }^{23}$ although further research is necessary.

The primary objective of the present study was to directly examine adult age differences in health-related quality of life in a sample of disaster survivors from south Louisiana who ranged in age from 18 to 91 years. A second objective was to examine the impact of social engagement on post-disaster physical and mental health outcomes. Many epidemiological studies document the associations among social relations and health, a topic of interest in the scientific community for many years. ${ }^{25,26}$ In this study, we conceptualized social engagement as an umbrella construct encompassing 2 social behaviors, namely, charitable work done for others and perceived social support (instrumental, appraisal, and emotional support). Ample evidence has shown that perceived social support ${ }^{27}$ and community-level support ${ }^{28}$ may lessen post-disaster distress. Cherry and colleagues ${ }^{4}$ found that social support was a protective factor for symptoms of depression and post-traumatic stress at least 5 years after Hurricanes Katrina and Rita. In the present study, we extend the literature by focusing on Katrina-related disruptions in charitable work done for others and the social support in the years before and after the 2005 hurricanes while controlling for the known influences of group, gender, education, income, objective health, and prior lifetime trauma. On the basis of previous literature, ${ }^{20}$ we expected that disruptions in social engagement activities would be inversely associated with health-related quality of life.

To summarize, the goals of this study were to (1) examine the impact of multiple disaster exposures on health-related quality of life in younger and older disaster survivors and (2) determine whether social engagement (defined as hurricane-related disruptions in charitable work done for others and social support) is associated with health-related quality of life. Taken together, the anticipated findings extend the literature on the long-term consequences of multiple disasters and may have noteworthy implications for the development of age-sensitive interventions to lessen distress among coastal residents exposed to a decade of disasters.

\section{METHODS}

\section{Participants}

In all, 219 people participated in this study. Sampling, recruitment, and testing are reported in greater detail elsewhere. ${ }^{4}$ Noncoastal and former coastal residents were 30 indirectly affected residents and 62 former coastal residents $(\mathrm{n}=92)$ who relocated permanently in 2005 to Baton
Rouge, Louisiana (mean age $=59.0$ years, $\mathrm{SD}=17.6$ years; age range, 18-91 years; 35 males, 57 females). There were 63 current coastal residents with catastrophic property damage and storm-related displacement in 2005; they returned to rebuild and had restored their lives in their original coastal communities (mean age $=60.7$ years, $\mathrm{SD}=15.0$ years; age range, 20-83 years; 26 males, 37 females). Current coastal fishers were 64 commercial fishers and their family members (mean age $=54.7$ years, $\mathrm{SD}=15.7$ years; age range, 21-90 years; 34 males, 30 females). Fishers were also coastal residents who were displaced for up to 2 years or more but who returned to rebuild after Katrina. Fishers had an additional layer of stress related to the $2010 \mathrm{BP}$ oil spill. That is, fishers are a particularly vulnerable group given their economic dependency on the Gulf of Mexico, which was severely impacted by the oil spill. Fishers could not work in the commercial fishing industry for up to 1 year or more after the spill. ${ }^{7,11,13}$

\section{Independent Measures}

All participants had completed a storm impact questionnaire with 4 modules: (1) hurricane exposure and threat to self/ family, (2) disruption and storm-related stressors (including property loss), (3) social support (charitable work done for others, availability of help if needed), and (4) lifetime exposure to potentially traumatic events. ${ }^{4}$ In this article, we utilized original data from the last 2 modules, with separate questions that assessed disruptions in charitable work done for others, perceived social support, and prior lifetime trauma, respectively. To be precise, we re-coded the original data from the third module in a binary manner, where $0=$ either no difference in or more charitable work after the 2005 hurricanes relative to before and $1=$ a decline in charitable work after the hurricanes. Similarly, perceived social support $=0$ if there was no difference or more social support and $1=$ there was a decline in social support after the storms.

Our rationale for the binary re-coding of these data here relative to an earlier report ${ }^{4}$ was to capture disruptions in these 2 social behaviors in a parsimonious manner that we could model in logistic regressions. Data from the third module (social support) included charitable work (eg, volunteer work at your church, synagogue or in the community; neighborly assistance to people in need) and availability of help if needed, which included instrumental support (eg, having someone to help you if you were confined to bed), appraisal support (eg, someone to give good advice about a crisis), and emotional support (eg, someone to love you and make you feel wanted). Data from the fourth module (lifetime trauma) were the sum of 5 events (other natural disaster, serious accident, attacked with a gun/knife/other weapon, attacked without weapon but with intent to kill/ injure, and experienced military combat or war zone), where each event was scored as 0 (no), 1 (yes, but no fear), or 2 (yes, with fear of injury or death during trauma). 


\section{Dependent Measures}

The Medical Outcomes Study Short Form-36 (SF-36) ${ }^{29}$ comprises 8 indicators of general health, including physical functioning, role limitations due to physical health problems, bodily pain, perceptions of general health, vitality, social functioning, role limitations due to emotional health problems, and mental health. The psychometric qualities of the SF-36 include construct validity ${ }^{30}$ and high internal consistency reliability for the 8 subscales. ${ }^{31}$ Subscales are combined to form composite physical (PCS) and mental (MCS) health component scores that range from 0 (lowest functioning) to 100 (highest functioning). Normative data yield a mean of 50 and a standard deviation of 10 for the PCS and MCS scores. ${ }^{32}$ Thus, we dichotomized these scores at 50 for the logistic regressions reported here.

\section{Statistical Analyses}

All statistical analyses were carried out by using SAS version 9.4 statistical software (SAS Institute Inc, Cary, NC). Prior research $^{2,15,21}$ has documented the potentially confounding influences of demographic factors (eg, gender, educational attainment, income), physical health, and lifetime traumatic events on post-disaster health and wellness indicators. Therefore, bivariate logistic regression analyses were run on all variables that might be expected to covary with health (not shown). Based on the outcomes of the bivariate analyses and prior literature, 6 variables were selected for inclusion as covariates in multivariate regression models, as follows: group (noncoastal and former coastal residents, current coastal residents, or current coastal fishers), gender, education (high school or less, some college or specialized training, college degree, or Master's/doctorate/professional degree), income ( $<\$ 2000 /$ month, $\$ 2000$ to $\$ 4000 /$ month, $\$ 4000$ to $\$ 6000 /$ month, or over $\$ 6000 /$ month), chronic physical conditions (dichotomized at 2 or more vs. less including high cholesterol, hypertension, diabetes, arthritis, cancer, and heart problems), and lifetime prior trauma. All outcomes were dichotomous.

\section{RESULTS}

\section{Psychosocial, Demographic, and Health Characteristics}

Table 1 presents a summary of the psychosocial, demographic, and self-reported health characteristics of the sample. The groups differed in prior lifetime trauma $(P=0.014)$, so these variables were controlled in the logistic regressions that follow. Gender composition was comparable across groups, but group membership was significantly associated with educational attainment by a chi-square test $(P<0.001)$. Noncoastal and former coastal residents reported holding a college degree or master's degree more often than expected: more than half of the fishers reported having a high school degree or less. Participants' self-reported income level fell short of statistical significance with group by a chi-square test $(P=0.066)$. The groups did not differ statistically in number of chronic conditions.

\section{Logistic Regression Analyses}

Odds ratios appear in Table 2 for 2 dimensions of social engagement, changes in charitable work done for others and perceived social support, before and after the 2005 storms. Inspection of Table 2 indicates that age was significantly and inversely associated with higher PCS scores $(\mathrm{OR}=0.15)$, which is consistent with the literature on post-disaster physical health in later life. ${ }^{22}$ Among the covariates, group (current coastal fishers, $\mathrm{OR}=0.34$ ) and objective health status ( 2 or more chronic conditions, $\mathrm{OR}=0.26$ ) were significantly inversely associated with higher PCS scores. Furthermore, low income $(<\$ 2000 /$ month, $\mathrm{OR}=0.33$, and $\$ 2000$ to $\$ 4000 /$ month, $\mathrm{OR}=0.26$ ) was inversely associated with SF-36 MCS scores. With respect to social engagement, only the decrease in perceived social support after the 2005 storms relative to a typical year before the storms was inversely associated with higher SF-36 MCS scores $(\mathrm{OR}=0.40)$. This aspect of the data indicates that participants were $60 \%$ less likely to have higher than average mental health with each additional point dropped on the social support ratings. Contrary to expectation, the drop in charitable work done for others since the 2005 storms was not associated with physical or mental health.

\section{DISCUSSION AND CONCLUSIONS}

Our primary objective in the present study was to examine adult age differences in health-related quality of life after a decade of consecutive disasters. In support of our hypothesis, we found that age was negatively associated with a higher than average SF-36 PCS composite score, which is composed of several subscales that measure of perceptions of physical functioning, ability to fulfill roles because of physical health problems, bodily pain, and general health. The age effect observed here was obtained after controlling for the known influences of group, gender, education, income, chronic conditions, and prior lifetime trauma. This finding joins others in the literature documenting lower perceptions of physical health among older persons compared to their younger counterparts. ${ }^{33}$ Interestingly, age was not associated with the SF-36 MCS composite score, implying that perceived mental health was no different for younger and older disaster survivors. To address the possibility that the null effect of age in the analysis of SF-36 MCS scores was an artifact of dividing the sample at the median ( 58 years), we conducted sensitivity analyses where we first treated age as a continuous variable and then as a dichotomous variable using a higher cutoff age: both analyses yielded the same null effect of age. The most conservative conclusion to be drawn based on these data and the follow-up sensitivity analyses is that older persons may not be differentially vulnerable to adverse post-disaster psychological sequelae, although further research would be desirable before firm conclusions are warranted. Participants in this study were community-dwelling adults and nearly all had prior hurricane and other natural disaster experience. ${ }^{4}$ Older adults with prior hurricane experience may possess effective problem-solving skills and coping 


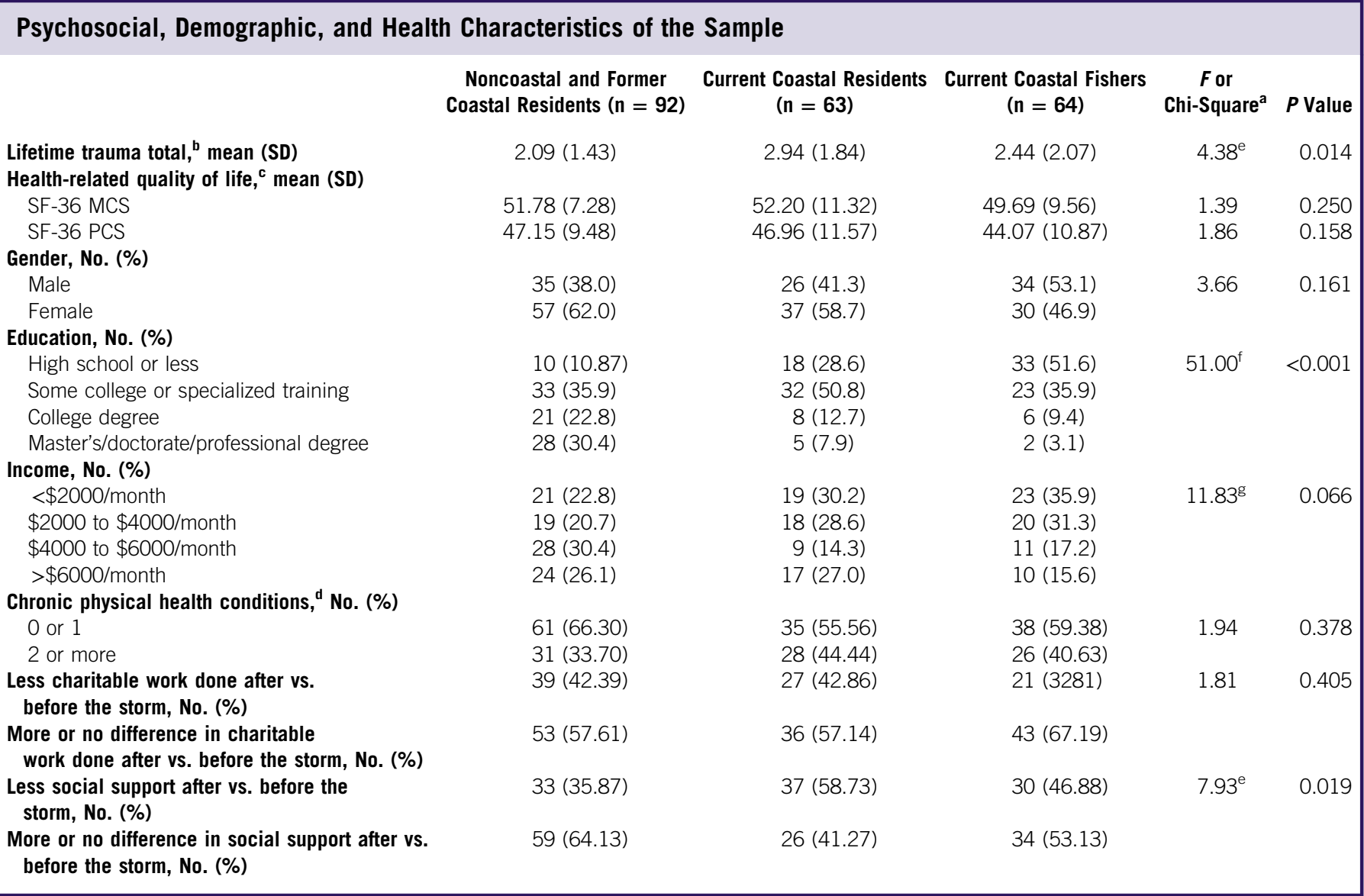

${ }^{\mathrm{a}} \mathrm{F}$ value for lifetime total trauma and health-related quality of life; chi-square for all other variables.

bifetime trauma with fear from Cherry et al. ${ }^{4}$

'SF-36 Health Survey, which includes composite indexes of physical (PCS) and mental (MCS) health. ${ }^{29}$

${ }^{\mathrm{d}}$ Based on the presence of 6 chronic conditions (high cholesterol, hypertension, diabetes, arthritis, cancer, and heart problems).

${ }^{\mathrm{e}} P \leq 0.05 ;{ }^{\mathrm{f}} P \leq 0.01 ;{ }^{\mathrm{g}} P>0.05$ and $\leq 0.10$.

strategies that could be positively impactful in future disaster preparation and relief planning. ${ }^{13,34}$ Frail older adults in the community and those with reduced health status in assistedliving or nursing home facilities may need special assistance for evacuation safety and post-disaster relocation, ${ }^{35,36}$ an important consideration for future disaster and emergency preparedness planning.

A second objective in this study was to examine the impact of social engagement on post-disaster health-related quality of life. We conceptualized social engagement as hurricanerelated disruptions in charitable work done for others and perceived social support after the storms, relative to a typical year before the 2005 storms. Disruption in charitable work was not significantly associated with physical or mental health. In contrast, the drop in perceived social support was significantly and inversely associated with SF-36 MCS scores. This aspect of the data is compatible with other findings showing that disruptions in social network characteristics have a deleterious effect on older Hurricane Katrina survivors. ${ }^{20}$ Our findings, among others in the disaster science literature, imply that perceived social support ${ }^{27}$ and community-level support ${ }^{28}$ may lessen post-disaster distress.

On a broader note, the group variable was treated as a covariate here to allow a clearer assessment of age-related differences in health-related quality of life. However, the inclusion of commercial fishers is a noteworthy strength of the study that deserves further comment. Because commercial fishers have been doubly affected by Katrina-related losses and the more recent economic impact of the BP oil spill disaster, they are at greater risk of adversity. ${ }^{9,11}$ The finding that group was a significant predictor of SF-36 PCS scores (commercial fishers, $\mathrm{OR}=0.34$ ) is suggestive of selfperceived health vulnerabilities among commercial fishers and their families with stressors related to the experience of natural and technological disasters in rapid succession. Relatively few studies have examined the mental and physical health consequences of natural and technological disaster exposures, although inherent differences between these 
TABLE 2

\section{Logistic Regressions Predicting PCS and MCS Composite Scores with Changes in Charitable Work Done for Others and Perceived Social Support as Predictors ${ }^{\mathrm{a}}$}

\begin{tabular}{|c|c|c|}
\hline & $\begin{array}{l}\text { SF-36 PCS 50+, } \\
\text { OR (95\% CI) }\end{array}$ & $\begin{array}{l}\text { SF-36 MCS } 50+ \\
\text { OR }(95 \% \mathrm{CI})\end{array}$ \\
\hline \multicolumn{3}{|l|}{ Age } \\
\hline Younger (<58 years) & 1.00 & 1.00 \\
\hline Ider ( $\geq 58$ years $)$ & $0.15^{\mathrm{c}}(0.07,0.35)$ & $1.76(0.80,3.84)$ \\
\hline \multicolumn{3}{|l|}{ Group } \\
\hline Noncoastal and former coastal residents & 1.00 & 1.00 \\
\hline Current coastal residents & $2.36^{\mathrm{d}}(0.95,5.89)$ & $2.03(0.87,4.73)$ \\
\hline Current coastal fishers & $0.34^{\mathrm{b}}(0.13,0.91)$ & $0.79(0.34,1.83)$ \\
\hline \multicolumn{3}{|l|}{ Education } \\
\hline High school or less & $0.52(0.15,1.80)$ & $1.26(0.38,4.24)$ \\
\hline Some college or specialized training & $0.81(0.28,2.38)$ & $0.86(0.29,2.51)$ \\
\hline College degree & $0.82(0.25,2.65)$ & $0.72(0.23,2.26)$ \\
\hline Master's/doctorate/professional Degree & 1.00 & 1.00 \\
\hline \multicolumn{3}{|l|}{ Gender } \\
\hline Female & 1.00 & 1.00 \\
\hline Male & $1.07(0.53,2.14)$ & $0.80(0.42,1.54)$ \\
\hline \multicolumn{3}{|l|}{ Income } \\
\hline$<\$ 2000 /$ month & $0.68(0.24,1.89)$ & $0.33^{\mathrm{b}}(0.12,0.88)$ \\
\hline$\$ 2000$ to $\$ 4000 /$ month & $1.93(0.71,5.23)$ & $0.26^{\mathrm{c}}(0.10,0.67)$ \\
\hline$\$ 4000$ to $\$ 6000 /$ month & $0.89(0.33,2.41)$ & $1.26(0.44,3.59)$ \\
\hline$>\$ 6000 /$ month & 1.00 & 1.00 \\
\hline Lifetime trauma total (with fear) & $0.83^{\mathrm{d}}(0.68,1.02)$ & $0.92(0.77,1.11)$ \\
\hline \multicolumn{3}{|l|}{ Objective physical health } \\
\hline 0 or 1 chronic physical conditions & 1.00 & 1.00 \\
\hline 2 or more chronic physical conditions & $0.26^{\mathrm{C}}(0.12,0.58)$ & $0.80(0.37,1.75)$ \\
\hline $\begin{array}{l}\text { Less charitable work done after (vs. before) } \\
\text { the } 2005 \text { storms }\end{array}$ & $0.63(0.30,1.30)$ & $0.83(0.44,1.58)$ \\
\hline $\begin{array}{l}\text { No difference or more charitable work after } \\
\text { (vs. before) the } 2005 \text { storms }\end{array}$ & 1.00 & 1.00 \\
\hline $\begin{array}{l}\text { Less social support/having someone else to } \\
\text { help you after (vs. before) the } 2005 \text { storms }\end{array}$ & $0.83(0.40,1.73)$ & $0.40^{c}(0.20,0.78)$ \\
\hline $\begin{array}{l}\text { No difference or more social support after } \\
\text { (vs. before) the } 2005 \text { storms }\end{array}$ & 1.00 & 1.00 \\
\hline
\end{tabular}

${ }^{a}$ Data for the SF-36 Health Survey, which includes composite indexes of physical (PCS) and mental (MCS) health. ${ }^{29}$

${ }^{\mathrm{b}} P \leq 0.05 ;{ }^{\mathrm{c}} P \leq 0.01 ;{ }^{\mathrm{d}} P>0.05$ and $\leq 0.10$.

different types of disaster are noted in the literature. For instance, natural disasters may bring sudden catastrophic damage and loss of life, although uncontrollable events of nature do happen from time to time and are generally not considered controversial. ${ }^{37-39}$ In contrast, technological disasters involve failure of a human-made system that is presumed to be controllable. ${ }^{37}$ For those directly impacted by technological disaster, a lengthy process of litigation may follow, as well as anger, hostility, and blame directed toward an individual or corporate entity at fault. ${ }^{40,41}$ Accordingly, technological disasters may have longer-lasting impacts on mental health and well-being for those directly affected, although further research to address different types of disaster and their long-term effects is necessary.

Last, we included chronic conditions and prior lifetime trauma (with fear for life or safety) among the covariates here based on the assumption that survivors' current health status and developmental history may shape post-disaster well-being after multiple consecutive disasters. The number of chronic conditions was predictive of SF-36 PCS scores as expected. This finding supports the notion that survivors' chronic conditions (an objective health indictor) impact health-related quality of life, a potentially important consideration for future disaster planning with older adults. Further, prior lifetime trauma was a marginally significant predictor $(P<0.10)$. Other evidence has shown that cumulative adversities, including life stressors and prior lifetime traumatic event exposures, affect the trajectories of mental and physical health in later life. ${ }^{21,42}$ Consideration of survivors' current health status and prior lifetime trauma is relevant for the design or implementation of programs in connection with disaster relief efforts. Future research to systematically explore the role that survivors' current health and developmental histories may play in the success of community-wide disaster relief programs would be valuable.

At least 4 methodological limitations of this study warrant brief mention. First, the sample size was small and may not be 
representative of the population. Second, a cross-sectional design was used, so causal inferences are not warranted. Healthrelated quality of life is likely to be dynamic, varying over time as people adapt to new life circumstances. Future research that includes longitudinal comparisons is needed to measure trajectories of change in health and psychological well-being among older disaster survivors. Third, we did not estimate the impact of variations in the temporal intervals between exposures to the 2005 hurricanes and 2010 BP oil spill and participants' responses on the outcome measures included here. The present results should be considered in light of this methodological limitation. Fourth, we did not include biological indicators of stress responses, a potentially important direction for future research to permit a more precise estimate of the long-term health consequences after a decade of disasters.

In closing, the present findings add to a growing literature on the human impacts of natural and technological disaster, bringing attention to older disaster survivors' physical and mental health risks in the years after these events. Interventions to address health challenges and health-related quality of life may be especially critical for commercial fishers in the years after disaster and are a potentially important direction that awaits future research.

\section{About the Authors}

Department of Psychology, Louisiana State University, Baton Rouge, Louisiana (Dr Cherry, Ms Baudoin, Ms Nezat, and Ms Stanko), School of Public Health, Boston University, Boston, Massachusetts (Ms Sampson and Dr Galea), and School of Family Life, Brigham Young University, Provo, Utah (Dr Marks).

Correspondence and reprint requests to Katie E. Cherry, Department of Psychology, Louisiana State University, Baton Rouge, LA 70803-5501 (e-mail: pskatie@lsu.edu).

\section{Acknowledgments}

We are grateful to Sr. Mary Keefe and Fr. John Arnone of Our Lady of Lourdes Catholic Church in Violet, Louisiana, for their assistance with recruitment. We thank Susan McNeil and Janet Hood of the St. Bernard Council on Aging, Sean Warner of the Gulf Coast Trust Bank in St. Bernard, and Todd Hamilton of Catholic Charities in Baton Rouge for their assistance and providing space for testing. We thank Kelli Broome, Susan Brigman, Ashley Cacamo, Mary Beth Tamor, Benjamin Staab, and Annie Crapanzano for their help with data collection and Bethany Lyon and Yaxin Lu for assistance with data scoring. We thank George Barisich, Gayle Buckley, Catherine Serpas, and Erin Walker for their contribution to the research effort.

\section{Funding}

This research was supported by grants from the Louisiana Board of Regents and the Louisiana State University Office of Research and Economic Development Gulf of Mexico Research Initiative (GRI) program. This support is gratefully acknowledged.

Published online: December 15, 2016.

\section{REFERENCES}

1. Neria Y, Galea S, Norris FH. eds. Mental Health and Disasters. New York, NY: Cambridge University Press; 2009. http://dx.doi.org/10.1017/ CBO9780511730030.
2. Norris FH, Elrod CL. Psychosocial consequences of disaster: A review of past research. In Norris FH, Galea S, Friedman MJ, et al, eds. Methods for Disaster Mental Health Research. New York, NY: Guilford Press; 2006:20-42.

3. Benight CC. Collective efficacy following a series of natural disasters. Anxiety Stress Coping. 2004;17(4):401-420. http://dx.doi.org/10.1080/ 10615800512331328768.

4. Cherry KE, Sampson L, Nezat PF, et al. Long-term psychological outcomes in older adults after disaster: relationships to religiosity and social support. Aging Ment Health. 2015;19(5):430-443. http://dx.doi.org/ 10.1080/13607863.2014.941325.

5. Fernandez WG, Galea S, Miller J, et al. Health status among emergency department patients approximately one year after consecutive disasters in New York City. Acad Emerg Med. 2005;12(10):958-964. http:// dx.doi.org/10.1111/j.1553-2712.2005.tb00807.x.

6. Osofsky JD, Osofsky HJ, Weems CF, et al. Effects of stress related to the Gulf Oil Spill on child and adolescent mental health. J Pediatr Psychol. 2016;41(1):65-72. http://dx.doi.org/10.1093/jpepsy/jsu085.

7. Cherry KE, Lyon BA, Marks LD, et al. After the BP Deepwater Horizon oil spill: financial and health concerns among coastal residents and commercial fishers. Curr Psychol. 2015;34(3):576-586. http://dx.doi.org/ 10.1007/s12144-015-9372-4.

8. Osofsky HJ, Osofsky JD. Hurricane Katrina and the Gulf oil spill: lessons learned. Psychiatr Clin North Am. 2013;36(3):371-383. http://dx.doi.org/ 10.1016/j.psc.2013.05.009.

9. Cherry KE, Marks LD, Adamek R, et al. Younger and older coastal fishers face catastrophic loss after Hurricane Katrina. In Cherry KE, ed. Traumatic Stress and Long-Term Recovery: Coping with Disasters and Other Negative Life Events. Cham, Switzerland: Springer International Publishing; 2015:327-348. http://dx.doi.org/10.1007/978-3-319-18866-9_18.

10. Lee MR, Blanchard TC. Community attachment and negative affective states in the context of the BP Deepwater Horizon disaster. Am Behav Sci. 2012;56(1):24-47. http://dx.doi.org/10.1177/0002764211409384.

11. Lyon BA, Nezat PF, Cherry KE, et al. When multiple disasters strike: Louisiana fishers in the aftermath of hurricanes and the British Petroleum Deepwater Horizon Oil Spill. In Cherry KE, ed. Traumatic Stress and Long-Term Recovery: Coping with Disasters and Other Negative Life Events. Cham, Switzerland: Springer International Publishing; 2015:57-70. http://dx.doi.org/10.1007/978-3-319-18866-9_4

12. Gill D, Ritchie L, Picou J, et al. The Exxon and BP oil spills: a comparison of psychosocial impacts. Nat Hazards. 2014; 74(3):1911-1932. http://dx.doi.org/10.1007/s11069-014-1280-7.

13. Cherry KE, Sampson L, Nezat PF, et al, Prior hurricane and other lifetime trauma predict coping style in older commercial fishers after the BP Deepwater Horizon oil spill. J Appl Biobehav Res. In press.

14. Galea S, Tracy M, Norris F, et al. Financial and social circumstances and the incidence and course of PTSD in Mississippi during the first two years after Hurricane Katrina. J Trauma Stress. 2008;21(4):357-368. http:// dx.doi.org/10.1002/jts. 20355 .

15. Norris FH, Friedman MJ, Watson PJ, et al. 60,000 disaster victims speak: part I. An empirical review of the empirical literature, 1981-2001. Psychiatry. 2002;65(3):207-239. http://dx.doi.org/10.1521/psyc.65.3.207.20173.

16. Bei B, Bryant C, Gilson KM, et al. A prospective study of the impact of floods on the mental and physical health of older adults. Aging Ment Health. 2013;17(8):992-1002. http://dx.doi.org/10.1080/13607863. 2013.799119.

17. Cherry KE, Allen PD, Galea S. Older adults and natural disasters: lessons learned from hurricanes Katrina and Rita. In Dass-Brailsford P, ed. Crisis and Disaster Counseling: Lessons Learned from Hurricane Katrina and Other Disasters. Thousand Oaks, CA: Sage Publications, Inc; 2010:115-130. http://dx.doi.org/10.4135/9781452275093.n8.

18. Cherry KE, Galea S, Silva JL. Successful aging and natural disasters: role of adaptation and resiliency in late life. In Hersen M, Gross AM, eds. Handbook of Clinical Psychology. Hoboken, NJ: John Wiley \& Sons; 2008:171-193.

19. Cherry KE, Silva JL, Galea S. Natural disasters and the oldest-old: a psychological perspective on coping and health in late life. In Cherry KE, ed. 
Lifespan Perspectives on Natural Disasters: Coping with Katrina, Rita, and Other Storms. New York, NY: Springer Science Business Media; 2009: 171-193. http://dx.doi.org/10.1007/978-1-4419-0393-8_9.

20. Roberto KA, Kamo Y, Henderson T. Encounters with Katrina: dynamics of older adults' social support networks. In Cherry KE, ed. Lifespan Perspectives on Natural Disasters: Coping with Katrina, Rita, and Other Storms. New York, NY: Springer Science Business Media; 2009:133-152. http://dx.doi.org/10.1007/978-1-4419-0393-8_7.

21. Tracy M, Galea S. Post-traumatic stress disorder and depression among older adults after a disaster: the role of ongoing trauma and stressors. Public Policy Aging Rep. 2006;16(2):16-19. http://dx.doi.org/10.1093/ ppar/16.2.16.

22. Silva Brown J, Cherry KE, Marks LD, et al. After Hurricanes Katrina and Rita: gender differences in health and religiosity in middle-aged and older adults. Health Care Women Int. 2010;31(11):997-1012. http:// dx.doi.org/10.1080/07399332.2010.514085.

23. Cherry KE, Silva Brown J, Marks LD, et al. Longitudinal assessment of cognitive and psychosocial functioning after Hurricanes Katrina and Rita: exploring disaster impact on middle-aged, older, and oldestold adults. J Appl Biobehav Res. 2011;16(3-4):187-211. http://dx.doi.org/ 10.1111/j.1751-9861.2011.00073.x.

24. Johnson J, Galea S. Disasters and population health. In Cherry KE, ed. Lifespan Perspectives on Natural Disasters: Coping with Katrina, Rita, and Other Storms. New York, NY: Springer Science Business Media; 2009:281-326. http://dx.doi.org/10.1007/978-1-4419-0393-8_14.

25. Berkman LF. The role of social relations in health promotion. Psychosom Med. 1995;57(3):245-254. http://dx.doi.org/10.1097/00006842-19950500000006.

26. House JS, Landis KR, Umberson D. Social relationships and health. Science. 1988;241(4865):540-545. http://dx.doi.org/10.1126/science.3399889.

27. Kaniasty K, Norris FH. Distinctions that matter: received social support, perceived social support, and social embeddedness after disasters. In Neria Y, Galea S, Norris FH, eds. Mental Health and Disasters. New York, NY: Cambridge University Press; 2012:175-200.

28. Norris FH, Stevens SP, Pfefferbaum B, et al. Community resilience as a metaphor, theory, set of capacities, and strategy for disaster readiness. Am J Community Psychol. 2008;41(1-2):127-150. http://dx.doi.org/10.1007/ s10464-007-9156-6.

29. Ware JE Jr, Sherbourne CD. The MOS 36-Item Short-Form Health Survey (SF-36): I. Conceptual framework and item selection. Med Care. 1992; 30(6):473-483. http://dx.doi.org/10.1097/00005650-199206000-00002.

30. McHorney CA, Ware JE, Raczek AE. The MOS 36-Item Short-Form Health Survey (SF-36): II. Psychometric and clinical tests of validity in measuring physical and mental health constructs. Med Care. 1993; 31(3):247-263. http://dx.doi.org/10.1097/00005650-199303000-00006.

31. McHorney CA, Ware JE, Lu JFR, Sherbourne CD. The MOS 36-Item Short-Form Health Survey (SF-36): III. Tests of data quality, scaling assumptions, and reliability across diverse patient groups. Med Care. 1994;32(1):40-66. http://dx.doi.org/10.1097/00005650-199401000-00004.

32. Ware JE, Kosinski M, Keller S. SF-36 physical and mental health summary scales: A user's manual. Health Assessment Lab. Boston, MA: The Health Institute; 1994.

33. Cherry KE, Walker EJ, Silva Brown J, et al. Social engagement and health in younger, older, and oldest-old adults in the Louisiana Healthy Aging Study. J Appl Gerontol. 2013;32(1):51-75. http://dx.doi.org/ 10.1177/0733464811409034.

34. Shenk D, Ramos B, Kalaw KJ, Tufan I. History, memory, and disasters among older adults: A life course perspective. Traumatology. 2009; 15(4):35-43. http://dx.doi.org/10.1177/1534765609359729.

35. Brown L, Christensen J, Ialynytchev A, et al. Experiences of assisted living facility staff in evacuating and sheltering residents during hurricanes. Curr Psychol. 2015;34(3):506-514. http://dx.doi.org/10.1007/s12144-0159361-7.

36. Allen PD, Nelson HW. Disaster services with frail older persons: from preparation to recovery. In Cherry KE, ed. Lifespan Perspectives on Natural Disasters: Coping with Katrina, Rita, and Other Storms. New York, NY: Springer Science Business Media; 2009:153-169. http://dx.doi.org/ 10.1007/978-1-4419-0393-8_8.

37. Baum A, Fleming R, Davidson LM. Natural disaster and technological catastrophe. Environ Behav. 1983;15(3):333-354. http://dx.doi.org/ 10.1177/0013916583153004.

38. Somasundaram D, Norris FH, Asukai N, et al. Natural and technological disasters. In Green BL, Friedman MJ, de Jong JTVM, et al, eds. Trauma Interventions in War and Peace. Springer, US: International and Cultural Psychology Series; 2004:291-318.

39. Kaniasty K, Norris FH. Social support in the aftermath of disasters, catastrophes, and acts of terrorism: altruistic, overwhelmed, uncertain, antagonistic, and patriotic communities. In Ursano RJ, Norwood AE, Fullerton CS, eds. Bioterrorism: Psychological and Public Health Interventions. New York, NY: Cambridge University Press; 2004:200-229.

40. Mayer B, Running K, Bergstrand K. Compensation and community corrosion: perceived inequalities, social comparisons, and competition following the Deepwater Horizon oil spill. Sociol Forum. 2015; 30(2):369-390. http://dx.doi.org/10.1111/socf.12167.

41. Cope MR, Slack T, Blanchard TC, et al. It's not whether you win or lose, it's how you place the blame: Shifting perceptions of recreancy in the context of the Deepwater Horizon Oil Spill. Rural Sociol. 2016;81(3):295-315. http://dx.doi.org/10.1111/ruso.12096. Accessed August 31, 2016.

42. Palgi Y, Shrira A, Shmotkin D. Aging with trauma across the lifetime and experiencing trauma in old age: vulnerability and resilience intertwined. In Cherry KE, ed. Traumatic Stress and Long-Term Recovery. Springer International Publishing; 2015:293-308. http://dx.doi.org/ 10.1007/978-3-319-18866-9_16. Accessed August 31, 2016. 